\title{
Multiple Accessory Cusps in Maxillary Primary Second Molars and Permanent First Molars and Its Clinical Implications
}

\author{
${ }^{1}$ Morankar Rahul, ${ }^{2}$ Goyal Ashima, ${ }^{3}$ Sanjeev Singh, ${ }^{4}$ Jaiswal Manoj, ${ }^{5}$ Gauba Krishan
}

\begin{abstract}
The primary and permanent teeth in humans may show anomalies related to numbers and morphology of crown and roots. There can be a variation in morphology, location, and prevalence of accessory cusps that can often lead to dental problems. The present case report is of a 9-year-old child exhibiting multiple accessory cusps on the occlusal surface of maxillary primary second molars and maxillary permanent first molars. This article highlights the clinical implications of condition and the associated problems.
\end{abstract}

Keywords: Central cusp, Clinical implications, Dens evaginatus, Multiple accessory cusps.

How to cite this article: Rahul M, Ashima G, Singh S, Manoj J, Krishan G. Multiple Accessory Cusps in Maxillary Primary Second Molars and Permanent First Molars and Its Clinical Implications. J Postgrad Med Edu Res 2018;52(3):143-146.

\section{Source of support: Nil}

Conflict of interest: None

\section{INTRODUCTION}

The primary and permanent teeth in humans may show variations in morphology. This variation can be seen involving the crown of a tooth in the form of accessory cusps or there can be an increase in the number of roots. However, in some cases, the variations in roots can be associated with anomalies of the crown. ${ }^{1}$ There can be a variation in the morphology and locations of accessory cusps. The most commonly reported accessory cusps are the Cusp of Carabelli in molars (68\%) followed by Leong's tubercle in premolars (8\%) and Talon's cusps in incisors $(1-7 \%))^{2,3}$

The etiology for such morphological aberrations is unclear. Earlier it was thought to be due to the overactivity of dental lamina. But recently a genetic control of

\footnotetext{
${ }^{1}$ Senior Resident, ${ }^{2,5}$ Professor, ${ }^{3}$ Junior Resident, ${ }^{4}$ Assistant Professor

${ }^{1-5}$ Department of Oral Health Sciences Center, Postgraduate Institute of Medical Education and Research, Chandigarh, India

Corresponding Author: Morankar Rahul, Senior Resident Department of Oral Health Sciences Center, Postgraduate Institute of Medical Education and Research, Chandigarh, India e-mail: captainrahul88@gmail.com
}

the process has been reported. The paired box 9 and Msh homeobox 1 genes are responsible for the abnormal shape of the teeth. ${ }^{4}$ The primary enamel knot appears during the late bud stage of tooth development and grows in size until the cap stage is reached. ${ }^{5}$ It regulates the advancing cuspal morphogenesis of the crown through expression of different molecules like bone morphogenetic proteins $2,4,7$, fibroblast growth factors 4,9 , and transforming growth factor- $\beta .^{6}$ It also regulates the expression of secondary enamel knots. The resultant cusp morphology and position are determined in a sequential manner. The cusps that are formed late in development are typically smaller than the main cusps. ${ }^{7}$

This article describes an accidental dental finding of bilateral anomalous central cusp and multiple accessory cusps in maxillary permanent first molars and maxillary primary second molars found in a case of mandibular fracture and also highlights in brief its clinical implications.

\section{CASE REPORT}

A 9-year-old child reported to the Oral Health Sciences Center, Postgraduate Institute of Medical Education and Research, Chandigarh, India, with the chief complaint of reduced mouth opening. History revealed trauma 4 days back due to road traffic accident. There was no history of unconsciousness, vomiting, and bleeding from ear or nose. Patient had restricted mouth opening and bilateral tenderness in temporomandibular joint region. Intraoral examination revealed deranged occlusion and step deformity at lower border of mandible in the symphysis region. The clinical findings and three-dimensional face computed tomography were suggestive of mandibular symphysis and bilateral condylar fractures (Fig. 1). Both condylar and symphysis fractures were managed conservatively with active mouth opening exercises. There was a significant improvement in mouth opening from baseline (9.5 $\mathrm{mm})$ to 2 years follow-up evaluation $(34.5 \mathrm{~mm})$.

Intraoral examination revealed central projection of cusps on the occlusal surface of maxillary permanent first molars and maxillary primary second molars bilaterally affecting 55, 65, 16, and 26 (Federation Dentaire Internationale notation). There was a prominent central projection 

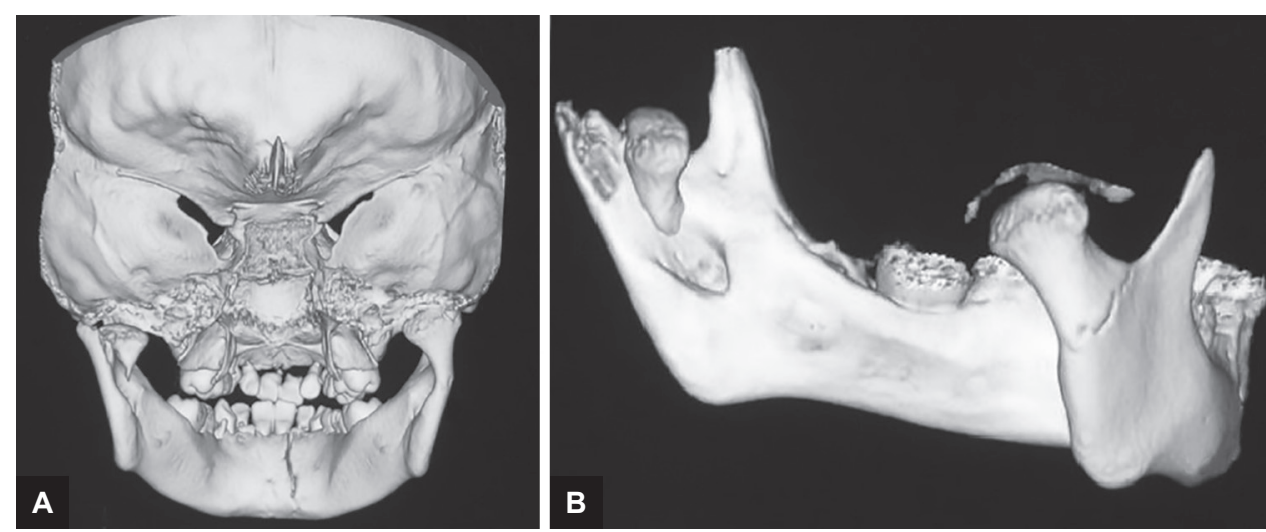

Figs $1 \mathrm{~A}$ and $\mathrm{B}$ : Three-dimensional face computed tomography. (A) Fracture involving mandibular symphysis region. (B) Bilateral condylar fracture

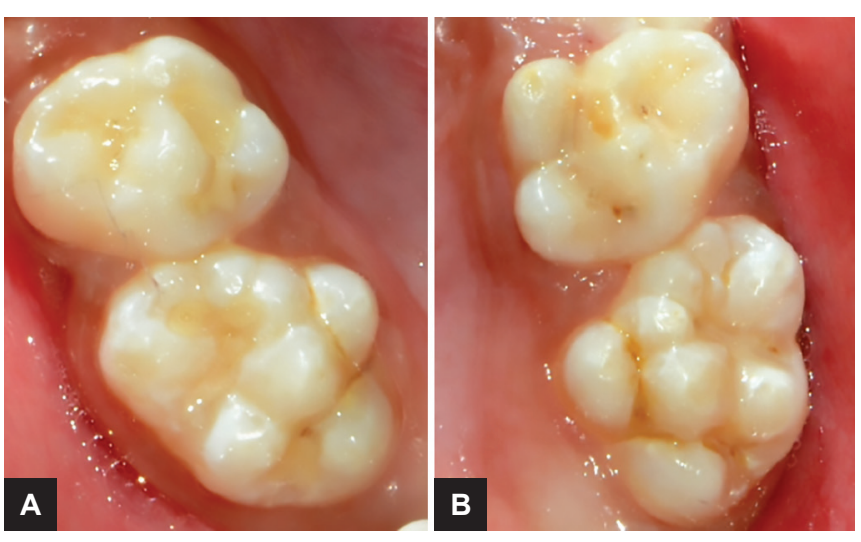

Figs 2A and B: Multiple accessory anomalous cusps on the occlusal surface of $55,16(A)$ and 65,26 with a prominent central projection (B)

on the occlusal surfaces of these teeth surrounded by six to seven small accessory cusps (Fig. 2). The demarcation of central oblique ridge was difficult due to the fusion of accessory cusps. Radiographic examination on intraoral periapical radiograph revealed normal crown and root development without any other abnormality in these teeth (Fig. 3). These cuspal projections were situated on a triangular base in the center of the oblique ridge. They were identical on both sides. These projections were smooth and rhomboidal in shape (Fig. 4). Medical history was noncontributory and no other family member was affected with similar condition. No other abnormalities related to systemic health or oral soft/hard tissues were present.

\section{DISCUSSION}

The central cusp also known as "dens evaginatus" is an accessory cusp and may or may not be associated with other accessory cusps. Several terminologies, such as supernumerary occlusal cusp, premolar odontome, occlusal tubercle, accessory central cusp, tuberculated premolar, and Leong's premolar are used to describe the central cusps on the occlusal surfaces of posterior teeth. ${ }^{8}$ It is composed of enamel and dentin with or without pulp projections. This anomaly is relatively rare with a wide variation in size, shape, and location. Schulze ${ }^{9}$ classification distinguishes the different types of central accessory cusps or dens evaginatus for posterior teeth according to the location of tubercles (Table 1). The condition is primarily reported in the people of Asian subcontinent with a reported prevalence of 2 to $8 \%$. It shows a typical bilateral symmetric distribution with a slight female
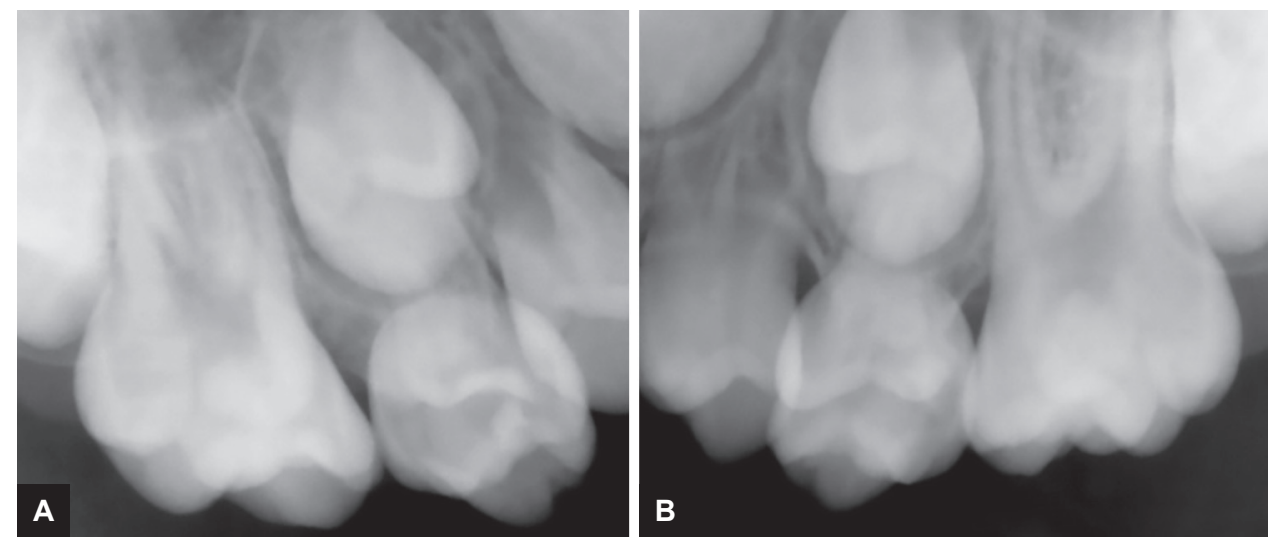

Figs $3 A$ and $B$ : Intraoral periapical radiograph showing normal development with 55,16 (A) and 65, 26 (B) 


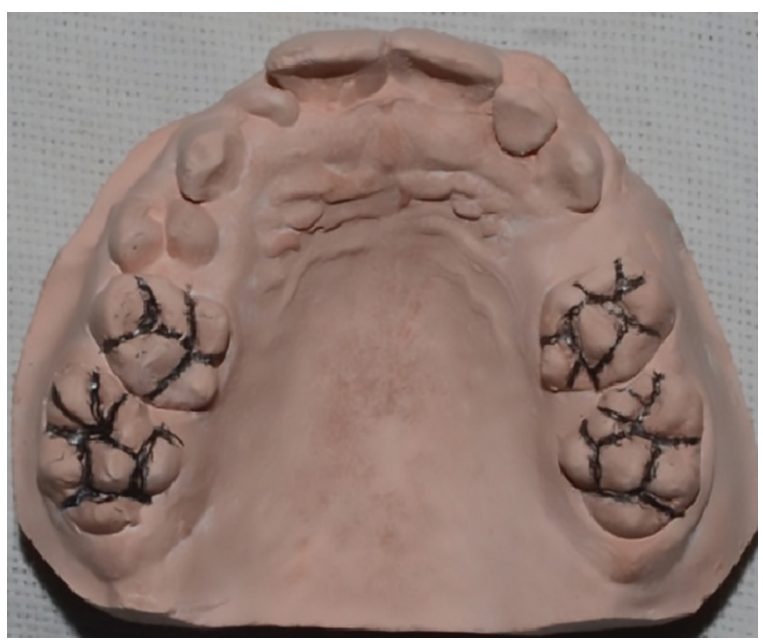

Fig. 4: Positive replica of maxillary arch showing distribution of multiple accessory cusps and grooves on occlusal surface of 55 , 65,16 , and 26

Table 1: Schulze ${ }^{9}$ classification of dens evaginatus or accessory cusps

A cone-like enlargement of the lingual cusp

A tubercle on the inclined plane of the lingual cusp

A cone-like enlargement of the buccal cusp

A tubercle on the inclined plane of the buccal cusp

A tubercle arising from the occlusal surface obliterating the central groove

predilection. ${ }^{8,10}$ Dens evaginatus can be found in any tooth but is most commonly associated with premolars. ${ }^{10}$ Studies have reported different prevalence rates of dens evaginatus for maxillary and mandibular arches, which varies according to the populations studied. ${ }^{10,11}$ Although no variation has been reported in the root canal anatomy, number, and position of canals in dens evaginatus cases, however, there can be a variation in the extent of pulp horns in accessory cusps. ${ }^{12}$

A correlation between the primary second molars and permanent first molars for presence of central cusp and multiple accessory cusps has not been reported in the literature. Studies have shown a high percentage of the succedaneous permanent teeth present with anomalies following its presence in primary dentition. ${ }^{13,14}$ Thus, presence of a dental anomaly in the primary dentition represents an increased likelihood of anomalies occurring in the permanent dentition. ${ }^{15}$

The presence of central cusp and associated multiple cusps is an anomaly of considerable clinical significance. It can often lead to occlusal interference. Maintaining a clean area between these cuspal elevations is very difficult. The presence of these extra cusps may lead to dental problems, such as caries in the pits or developmental grooves between the accessory cusp and the tooth. It can also lead to sensitivity. ${ }^{16}$ Banding procedure is also very difficult to perform due to unusual morphology of these teeth, making proper adaptation of bands difficult. This poses a great difficulty for orthodontic treatment and can also lead to tooth demineralization and caries development. ${ }^{17}$

Early detection and management of this condition is important because trauma during mastication can cause fracture or wear of these tubercles and can lead to necrosis of pulp and periapical infection. There are possibilities of pulp exposure during early phases of root development, resulting in pulp necrosis and an incompletely formed root. ${ }^{18}$ In a vital tooth with such an accessory occlusal cusps, selective reduction of opposing occluding teeth can be done. In a situation where the tubercle has fractured, it can be sealed with resin composite. Early diagnosis is important so that preventive management can be started as early as possible.

\section{CONCLUSION}

This article represents a rare case of bilateral anomalous multiple accessory cusps on the occlusal surface of primary and permanent molars. Early diagnosis and institution of preventive measures can help to prevent dental problems associated with the condition.

\section{CLINICAL SIGNIFICANCE}

Early diagnosis and preventive interventions help to prevent dental complications of dens evaginatus.

\section{REFERENCES}

1. Kallay J. Extra cusp formation in the human dentition. J Dent Res 1966 Sep-Oct;45(5):1381-1394.

2. Ooshima T, Ishida R, Mishima K, Sobue S. The prevalence of developmental anomalies of teeth and their association with tooth size in the primary and permanent dentitions of 1650 Japanese children. Int J Paediatr Dent 1996 Jun;6(2):87-94.

3. Nirmala S, Challa R, Velpula L, Nuvvula S. Unusual occurrence of accessory central cusp in the maxillary second primary molar. Contemp Clin Dent 2011 Apr-Jun;2(2):127-130.

4. Sedano HO, Ocampo-Acosta F, Naranjo-Corona RI, TorresArellano ME. Multiple dens invaginatus, mulberry molar and conical teeth. Case report and genetic considerations. Med Oral Patol Oral Cir Bucal 2009 Feb;14(2):E69-E72.

5. Hargreaves K, Goodis H, editors. Seltzer and Bender's dental pulp. 1st ed. Chicago: Quintessence Publishing; 2002. pp. 13-17.

6. Thesleff I, Keranen S, Jernvall J. Enamel knots as signaling centers linking tooth morphogenesis and odontoblast differentiation. Adv Dent Res 2001 Aug;15:14-18.

7. Thesleff I. Epithelial-mesenchymal signaling regulating tooth morphogenesis. J Cell Sci 2003 May;116(Pt 9):1647-1648.

8. Kocsis GS, Marcsik A, Kokai EL, Kocsis KS. Supernumerary occlusal cusps on permanent human teeth. Acta Biol Szeged 2002;46(1-2):71-82.

9. Schulze $\mathrm{CH}$. Anomalien and Missbildungen der menschlichen Zahne. Berlin: Quintessenz Verlags GmbH; 1987. pp. 94-101.

10. Hill F, Bellis W. Dens evaginatus and its management. Br Dent J 1984 Jun;156(11):400-402. 
11. Merrill RG. Occlusal anomalous tubercles on premolars of Alaskan Eskimos and Indians. Oral Surg Oral Med Oral Pathol 1964 Apr;17:484-496.

12. Oehlers F, Lee K, Lee E. Dens evaginatus (evaginated odontome): its structure and responses to external stimuli. Dent Pract Dent Rec 1967 Mar;17(7):239-244.

13. Nik-Hussein NN, Abdul Majid Z. Dental anomalies in the primary dentition: distribution and correlation with the permanent dentition. J Clin Pediatr Dent 1996 Fall;21(1):15-19.

14. Whittington BR, Durward CS. Survey of anomalies in primary teeth and their correlation with the permanent dentition. N Z Dent J 1996 Mar;92(407):4-8.
15. Marinelli A, Giuntini V, Franchi L, Tollaro I, Baccetti T, Defraia E. Dental anomalies in the primary dentition and their repetition in the permanent dentition: a diagnostic performance study. Odontology 2012 Jan;100(1):22-27

16. Stecker S, DiAngelis AJ. Dens evaginatus: a diagnostic and treatment challenge. J Am Dent Assoc 2002 Feb;133(2):190-193.

17. Falomo OO. The cusp of Carabelli: frequency, distribution, size and clinical significance in Nigeria. West Afr J Med 2002 Oct-Dec;21(4):322-324.

18. Chu FC, Sham AS, Yip KH. Fractured dens evaginatus and unusual periapical radiolucency. Dent Traumatol 2002 Dec;18(6):339-341. 